\title{
Horizon-K Farsightedness in Criminal Networks
}

Citation for published version (APA):

Herings, P. J-J., Mauleon, A., \& Vannetelbosch, V. (2021). Horizon-K Farsightedness in Criminal Networks. Maastricht University, Graduate School of Business and Economics. GSBE Research Memoranda No. 008 https://doi.org/10.26481/umagsb.2021008

Document status and date:

Published: 04/05/2021

DOI:

10.26481/umagsb.2021008

Document Version:

Publisher's PDF, also known as Version of record

\section{Please check the document version of this publication:}

- A submitted manuscript is the version of the article upon submission and before peer-review. There can be important differences between the submitted version and the official published version of record.

People interested in the research are advised to contact the author for the final version of the publication, or visit the DOI to the publisher's website.

- The final author version and the galley proof are versions of the publication after peer review.

- The final published version features the final layout of the paper including the volume, issue and page numbers.

Link to publication

\footnotetext{
General rights rights.

- You may freely distribute the URL identifying the publication in the public portal. please follow below link for the End User Agreement:

www.umlib.nl/taverne-license

Take down policy

If you believe that this document breaches copyright please contact us at:

repository@maastrichtuniversity.nl

providing details and we will investigate your claim.
}

Copyright and moral rights for the publications made accessible in the public portal are retained by the authors and/or other copyright owners and it is a condition of accessing publications that users recognise and abide by the legal requirements associated with these

- Users may download and print one copy of any publication from the public portal for the purpose of private study or research.

- You may not further distribute the material or use it for any profit-making activity or commercial gain

If the publication is distributed under the terms of Article $25 \mathrm{fa}$ of the Dutch Copyright Act, indicated by the "Taverne" license above, 
P. Jean-Jacques Herings,

Ana Mauleon, Vincent Vannetelbosch

Horizon-K Farsightedness in Criminal Networks

$\mathrm{RM} / 21 / 008$

ISSN: $2666-8807$

\section{GSBE}

Maastricht University School of Business and Economics

Graduate School of Business and Economics

\section{P.O Box 616}

NL- 6200 MD Maastricht

The Netherlands 


\title{
Horizon- $K$ Farsightedness in Criminal Networks
}

\author{
P. Jean-Jacques Herings* Ana Mauleon ${ }^{\dagger}$ \\ Vincent Vannetelbosch ${ }^{\ddagger}$
}

April 23, 2021

\begin{abstract}
We study the criminal networks that will emerge in the long run when criminals are neither myopic nor completely farsighted but have some limited degree of farsightedness. We adopt the horizon- $K$ farsighted set of Herings, Mauleon and Vannetelbosch (2019) to answer this question. We find that in criminal networks with $n$ criminals, the set consisting of the complete network is a horizon- $K$ farsighted set whenever the degree of farsightedness of the criminals is larger than or equal to $(n-1)$. Moreover, the complete network is the unique horizon- $(n-1)$ farsighted set. Hence, the predictions obtained in case of completely farsighted criminals still hold when criminals are much less farsighted.
\end{abstract}

Key words: Limited farsightedness, Stability, Criminal Networks. JEL classification: A14; C70; D20.

${ }^{*}$ Department of Economics, Maastricht University, Maastricht, The Netherlands. E-mail: P.Herings@maastrichtuniversity.nl

${ }^{\dagger}$ CEREC, UCLouvain Saint-Louis - Brussels; CORE, UCLouvain, Louvain-la-Neuve, Belgium. E-mail: ana.mauleon@usaintlouis.be

${ }^{\ddagger}$ CORE, UCLouvain, Louvain-la-Neuve; CEREC, UCLouvain Saint-Louis - Brussels, Belgium. E-mail: vincent.vannetelbosch@uclouvain.be 


\section{Introduction}

There is empirical evidence suggesting that peer effects and the structure of social interactions matter strongly in explaining an individual's own criminal or delinquent behavior. ${ }^{1}$ A criminal's place in the network and the know-how on the crime business of his partners determine his criminal opportunities and constraints, as well as his information about these opportunities and constraints. It is therefore crucial to understand how such criminal networks are formed and structured, and how they evolve and perform.

Different ways of characterizing which network structures are stable have been proposed in the literature depending on whether (and how far) agents anticipate that their action may also induce others to change the network relations they maintain. The notion of pairwise stable network, introduced by Jackson and Wolinsky (1996), assumes that agents are able to modify the network one link at a time, and choose to change the network if the resulting network implies higher payoffs for the deviating agents. As such, pairwise stability involves fully myopic agents in the sense that they do not anticipate that others might react to their actions. At the other extreme end of the spectrum, a number of solution concepts involve perfectly farsighted agents, i.e., agents that fully anticipate the complete sequence of reactions that results from their own actions in the network. However, this assumption of perfect farsightedness, especially when the number of agents becomes large, requires a very high level of foresight on behalf of the agents. Kirchsteiger, Mantovani, Mauleon and Vannetelbosch (2016) provide experimental evidence suggesting that subjects are consistent with an intermediate rule of behavior, which can be interpreted as a form of limited farsightedness. Agents only anticipate a limited number of reactions by the other agents to the actions they take themselves. ${ }^{2}$ In this paper, we study the criminal networks that agents form when criminals are neither fully myopic nor completely farsighted but have some limited degree of farsightedness. In other words, we show how the predictions about stable criminal networks relate to the degree of farsightedness.

There is a large literature on the economics of crime. Calvo-Armengol and Zenou (2004) provide a network analysis of criminal behavior. They develop a model where

\footnotetext{
${ }^{1}$ See Patacchini and Zenou (2008) among others.

${ }^{2}$ Similar experimental evidence for limited farsightedness is found in van Dolder and Buskens (2014).
} 
criminals compete with each other in criminal activities but benefit from being friends with other criminals by improving their knowledge of the crime business. Individuals decide first whether to work or to become a criminal and then they choose the crime effort to exert conditional on being a criminal. ${ }^{3}$ Ballester, Calvo-Armengol and Zenou (2010) develop a criminal network game where each delinquent decides how much delinquency effort to exert. The network is determined endogenously by allowing players to join the labor market instead of committing criminal activities. They find that the optimal enforcement policy consists of removing some key player or some key group. Such a policy is complex since it depends both on the wage and on the network. Indeed, the removal of some players may induce further voluntary moves of other players who now find it profitable to leave their criminal activities and join the labor market. ${ }^{4}$

In this paper we present a simplified version of the model of Calvo-Armengol and Zenou (2004) which puts emphasis on the formation of links and keeps the level of criminal activities of the players fixed. For simplicity, we also keep the wage on the labor market small enough in Calvo-Armengol and Zenou's model so that all individuals prefer to become a criminal whatever the social network connecting the criminals. By doing so, we study the networks that will be formed when criminals have the discretion to choose their connections.

Herings, Mauleon and Vannetelbosch (2009) introduce the notion of a pairwise farsightedly stable set to study the networks that will be formed by farsighted players. ${ }^{5}$ Herings, Mauleon and Vannetelbosch (2009) analyze a simplified version of the criminal network model of Calvo-Armengol and Zenou (2004) and find that, in criminal networks with 3 players, there may be several pairwise stable networks but the set consisting of the complete network, where all criminals are linked to each other, is the unique pairwise farsightedly stable set. Moreover, they show that the complete network is a pairwise farsightedly stable set for any number of players.

\footnotetext{
${ }^{3}$ Calvo-Armengol and Zenou (2004) mostly focus on the case where the network is exogenously given. They show that multiple equilibria with different members of active criminals and levels of involvement in crime business may coexist.

${ }^{4}$ See also Bezin, Verdier and Zenou (2021) and Lee, Liu, Patacchini and Zenou (2021).

${ }^{5}$ Other approaches to farsightedness in network formation are suggested by the work of Chwe (1994), Xue (1998), Herings, Mauleon and Vannetelbosch (2004), Mauleon and Vannetelbosch (2004), Dutta, Ghosal and Ray (2005), Page, Wooders and Kamat (2005), Page and Wooders (2009), Mauleon, Vannetelbosch and Vergote (2011), and Ray and Vohra (2015).
} 
Which are the criminal networks that will emerge in the long run when criminals have a limited degree of farsightedness? We adopt the horizon- $K$ farsighted set of Herings, Mauleon and Vannetelbosch (2019) to answer this question. The concept encompasses both the pairwise farsightedly stable set and the pairwise myopically stable set introduced by Herings, Mauleon and Vannetelbosch (2009). ${ }^{6}$

A set of networks $G_{K}$ is a horizon- $K$ farsighted set if three conditions are satisfied. First, deviations outside the set should be horizon- $K$ deterred. Second, horizon- $K$ external stability is required. That is, from any network outside of $G_{K}$ there is a sequence of farsighted improving paths of length smaller than or equal to $K$ leading to some network in $G_{K}$. Third, a minimality condition is required. That is, there is no proper subset of $G_{K}$ satisfying the first two conditions. Herings, Mauleon and Vannetelbosch (2019) show that a horizon- $K$ farsighted set always exists and provide easy to verify conditions for a set of networks to be a horizon- $K$ farsighted set.

In this paper, we find that in criminal networks with $n$ criminals, the set consisting of the complete network is a horizon- $K$ farsighted set whenever the degree of farsightedness of the criminals is larger or equal than $(n-1)$. Moreover, the complete network is the unique horizon- $(n-1)$ farsighted set. Hence, we obtain a very sharp prediction for intermediate degrees of farsightedness (i.e., have a degree of farsightedness equal to $n-1$ ), and show that a limited degree of farsightedness (i.e., at least $n-1$ ) is sufficient to recover the predictions obtained in case of completely farsighted criminals. Knowledge about the degree of farsightedness of criminals is therefore important to determine which criminal networks are likely to emerge in the long run and to implement adequate delinquency-reducing policies.

The paper is organized as follows. In Section 2 we introduce some notations and basic properties of criminal networks. In Section 3 we define the notion of a horizon- $K$ farsighted set. In Section 4 we identify the horizon- $K$ farsighted set of criminal networks. Finally, in Section 5 we conclude.

\footnotetext{
${ }^{6}$ The myopic stable set of Demuynck, Herings, Saulle, and Seel (2019) generalizes the pairwise myopically stable set to a large class of social environments and shows how it unifies the most important concepts of non-cooperative game theory like Nash equilibrium and cooperative game theory like the core.
} 


\section{Criminal Networks}

Let $N=\{1, \ldots, n\}$ be the finite set of criminals. Throughout the paper, we assume that $n \geq 3$. A criminal network $g$ is simply a list of which pairs of criminals are linked to each other and $i j \in g$ indicates that $i$ and $j$ are linked under $g$. The complete network on the set of criminals $S \subseteq N$ is denoted by $g^{S}$ and is equal to the set of all subsets of $S$ of size $2 .^{7}$ It follows in particular that the empty network is denoted by $g^{\emptyset}$. Let $g_{\mid S}=\{i j \in g \mid i, j \in S\}$ be the network found by deleting all links from $g$ except those that are between players in $S$. The set of all possible networks or graphs on $N$ is denoted by $\mathbb{G}$ and consists of all subsets of $g^{N}$. The cardinality of $\mathbb{G}$ is denoted by $n^{\prime}=2^{n(n-1) / 2}$.

The network obtained by adding link $i j$ to network $g$ is denoted by $g+i j$ and the network that results from deleting link $i j$ from network $g$ by $g-i j$. Let $N(g)=$ $\{i \in N \mid \exists j \in N$ such that $i j \in g\}$ be the set of criminals who have at least one link in the network $g$. A path in a network $g \in \mathbb{G}$ between criminals $i$ and $j$ of length $K \geq 1$ is a finite sequence of criminals $i_{0}, \ldots, i_{K}$ with $i_{0}=i$ and $i_{K}=j$ such that for any $k \in\{0, \ldots, K-1\}, i_{k} i_{k+1} \in g$, and such that each criminal in the sequence $i_{0}, \ldots, i_{K}$ is distinct. A network $g$ is connected if for each pair of criminals $i$ and $j$ in $N(g)$ such that $i \neq j$ there exists a path between $i$ and $j$ in $g$. A non-empty network $h \subseteq g$ is a component of $g$ if $h$ is connected and and for any $i \in N(h)$ and $j \in N(g), i j \in g$ implies $i j \in h$. The set of components of $g$ is denoted by $C(g)$. Knowing the components of a network, we can partition the criminals into maximal groups within which criminals are connected. Let $\mathcal{P}(g)$ denote the partition of $N$ into components and singletons induced by the network $g$. That is, the set $S$ of players belongs to $\mathcal{P}(g)$ if and only if either there exists a network $h$ in $C(g)$ such that $S=N(h)$ or there exists $i \notin N(g)$ such that $S=\{i\}$.

Next, we present a simplified version of the model of Calvo-Armengol and Zenou (2004). Given some criminal network $g$, the elements of $\mathcal{P}(g)$ are called criminal groups. Each criminal group $S$ has a positive probability $\pi_{S}(g)$ of winning the loot $B>0$. It is assumed that the bigger the criminal group, the higher its probability of getting the loot. This assumption captures the idea that delinquents learn from other criminals belonging to the same group how to commit crime in a more efficient way by sharing the know-how about the technology of crime. We assume that the

\footnotetext{
${ }^{7}$ Throughout the paper we use the notation $\subseteq$ for weak inclusion and $\varsubsetneqq$ for strict inclusion. Finally, the notation \# is used for the cardinality of a set.
} 
probability of winning the loot is given by $\pi_{S}(g)=\# S / n$.

The network architecture determines how the loot is shared among the criminals in the group. Consider some criminal $i \in N$ and let $S \in \mathcal{P}(g)$ be the criminal group $i$ belongs to. Let $d_{i}(g)$ denote the degree of criminal $i$ in $g$; i.e., the number of links criminal $i$ has in $g$. We define $c_{i}(g)=\max _{j \in S} d_{j}(g)$ as the maximum degree in this criminal group. A criminal $i$ who is part of a group $S \in \mathcal{P}(g)$ expects a share $\alpha_{i}(g)$ of the loot given by

$$
\alpha_{i}(g)= \begin{cases}\frac{1}{\#\left\{j \in S \mid d_{j}(g)=c_{j}(g)\right\}}, & \text { if } d_{i}(g)=c_{i}(g), \\ 0, & \text { otherwise. }\end{cases}
$$

That is, within each criminal group, the criminal that has the highest number of links gets the loot. If two or more criminals have the highest number of links, then they share the loot equally among them.

Criminal $i$ has a probability $q_{i}(g)$ of being caught, in which case his rewards are punished at a rate $\phi>0$. It is assumed that the higher the number of links a criminal has, the lower his individual probability of being caught. We assume that the probability of being caught is simply given by

$$
q_{i}(g)=\frac{n-1-d_{i}(g)}{n} .
$$

The total payoffs of criminal $i$ belonging to criminal group $S \in \mathcal{P}(g)$ are therefore equal to

$$
\begin{aligned}
Y_{i}(g) & =\pi_{S}(g) \alpha_{i}(g)\left(1-q_{i}(g) \phi\right) B \\
& = \begin{cases}\frac{\# S}{n} \frac{1}{1} \#\left\{j \in S \mid d_{j}(g)=c_{i}(g)\right\}\left(1-\frac{n-1-d_{i}(g)}{n} \phi\right) B, & \text { if } d_{i}(g)=c_{i}(g), \\
0, & \text { otherwise. }\end{cases}
\end{aligned}
$$

We require $\phi<n /(n-1)$ to guarantee that payoffs are non-negative and positive for a criminal with the highest degree in his group.

\section{Horizon- $K$ Farsighted Set}

We propose the notion of horizon- $K$ farsighted set introduced by Herings, Mauleon and Vannetelbosch (2019) to determine the criminal networks that emerge in the long run when criminals are neither fully myopic nor completely farsighted but have some limited degree of farsightedness. 
A farsighted improving path of length $K \geq 1$ from a network $g$ to a network $g^{\prime}$ is a finite sequence of networks $g_{0}, \ldots, g_{K}$ with $g_{0}=g$ and $g_{K}=g^{\prime}$ such that for any $k \in\{1, \ldots, K-1\}$ either (i) $g_{k+1}=g_{k}-i j$ for some $i j$ such that $Y_{i}\left(g_{K}\right)>Y_{i}\left(g_{k}\right)$ or $Y_{j}\left(g_{K}\right)>Y_{j}\left(g_{k}\right)$, or (ii) $g_{k+1}=g_{k}+i j$ for some $i j$ such that $Y_{i}\left(g_{K}\right)>Y_{i}\left(g_{k}\right)$ and $Y_{j}\left(g_{K}\right) \geq Y_{j}\left(g_{k}\right)$. If there exists a farsighted improving path of length $K$ from $g$ to $g^{\prime}$, then we write $g \rightarrow_{K} g^{\prime}$. For a given network $g$ and some $K^{\prime} \geq 0$, let $f_{K^{\prime}}(g)$ be the set of networks that can be reached from $g$ by a farsighted improving path of length $K \leq K^{\prime}$. That is, $f_{K^{\prime}}(g)=\left\{g^{\prime} \in \mathbb{G} \mid \exists K \leq K^{\prime}\right.$ such that $\left.g \rightarrow_{K} g^{\prime}\right\}$. Let $f_{\infty}(g)=\left\{g^{\prime} \in \mathbb{G} \mid \exists K \in \mathbb{N}\right.$ such that $\left.g \rightarrow_{K} g^{\prime}\right\}$ denote the set of networks that can be reached from $g$ by some farsighted improving path. Lemma 1 in Herings, Mauleon and Vannetelbosch (2019) shows that for every $K \geq 1$, for every $g \in \mathbb{G}$, it holds that $f_{K}(g) \subseteq f_{K+1}(g)$, and that for $K \geq n^{\prime}-1$, for every $g \in \mathbb{G}$, it holds that $f_{K}(g)=f_{K+1}(g)=f_{\infty}(g)$.

An important concept in the analysis of networks is the one of pairwise stability as introduced in Jackson and Wolinsky (1996). A network $g \in \mathbb{G}$ is pairwise stable if (i) for every $i j \in g, Y_{i}(g) \geq Y_{i}(g-i j)$ and $Y_{j}(g) \geq Y_{j}(g-i j)$, and (ii) for every ij $\notin g$, if $Y_{i}(g)<Y_{i}(g+i j)$, then $Y_{j}(g)>Y_{j}(g+i j)$. We say that a network $g^{\prime}$ is adjacent to $g$ if $g^{\prime}=g+i j$ or $g^{\prime}=g-i j$ for some $i j$. A network $g^{\prime}$ defeats $g$ if either $g^{\prime}=g-i j$ and $Y_{i}\left(g^{\prime}\right)>Y_{i}(g)$ or $Y_{j}\left(g^{\prime}\right)>Y_{j}(g)$, or if $g^{\prime}=g+i j$ with $\left(Y_{i}\left(g^{\prime}\right), Y_{j}\left(g^{\prime}\right)\right)>\left(Y_{i}(g), Y_{j}(g)\right){ }^{8}$ A network is pairwise stable if and only if it is not defeated by another network. It is also easy to see that $g^{\prime} \in f_{1}(g)$ if and only if $g^{\prime}$ defeats $g$. We can therefore define the pairwise stable networks $P_{1}$ as those $g \in \mathbb{G}$ for which $f_{1}(g)=\emptyset$. For $K \geq 1$, let $P_{K}=\left\{g \in \mathbb{G} \mid f_{K}(g)=\emptyset\right\}$ denote the set of horizon-K pairwise stable networks. ${ }^{9}$

A refinement of pairwise stability is obtained when we require the network $g$ to defeat every other adjacent network, so $g \in f_{1}\left(g^{\prime}\right)$ for every network $g^{\prime}$ adjacent to g. We call such a network $g$ pairwise dominant. For $K \geq 1$, a network $g \in \mathbb{G}$ is horizon-K pairwise dominant if for every $g^{\prime}$ adjacent to $g$ it holds that $g \in f_{K}\left(g^{\prime}\right)$. The set of horizon-K pairwise dominant networks is denoted by $D_{K}$.

\footnotetext{
${ }^{8}$ We use the notation $\left(Y_{i}\left(g^{\prime}\right), Y_{j}\left(g^{\prime}\right)\right)>\left(Y_{i}(g), Y_{j}(g)\right)$ for $Y_{i}\left(g^{\prime}\right) \geq Y_{i}(g)$ and $Y_{j}\left(g^{\prime}\right) \geq Y_{j}(g)$ with at least one inequality holding strictly, $\left(Y_{i}\left(g^{\prime}\right), Y_{j}\left(g^{\prime}\right)\right) \geq\left(Y_{i}(g), Y_{j}(g)\right)$ for $Y_{i}\left(g^{\prime}\right) \geq Y_{i}(g)$ and $Y_{j}\left(g^{\prime}\right) \geq Y_{j}(g)$, and $\left(Y_{i}\left(g^{\prime}\right), Y_{j}\left(g^{\prime}\right)\right) \gg\left(Y_{i}(g), Y_{j}(g)\right)$ for $Y_{i}\left(g^{\prime}\right)>Y_{i}(g)$ and $Y_{j}\left(g^{\prime}\right)>Y_{j}(g)$.

${ }^{9}$ Jackson (2008) defines a network to be farsightedly pairwise stable if there is no farsighted improving path emanating from it. This concept reverts to $P_{\infty}$ and refines the set of pairwise stable networks.
} 
The set $f_{K}^{2}(g)=f_{K}\left(f_{K}(g)\right)=\left\{g^{\prime \prime} \in \mathbb{G} \mid \exists g^{\prime} \in f_{K}(g)\right.$ such that $\left.g^{\prime \prime} \in f_{K}\left(g^{\prime}\right)\right\}$ consists of those networks that can be reached by a composition of two farsighted improving paths of length at most $K$ from $g$. We extend this definition and, for $m \in \mathbb{N}$, we define $f_{K}^{m}(g)$ as those networks that can be reached from $g$ by means of $m$ compositions of farsighted improving paths of length at most $K$. Let $f_{K}^{\infty}$ denote the set of networks that can be reached from $g$ by means of any number of compositions of farsighted improving paths of length at most $K$. Lemma 2 in Herings, Mauleon and Vannetelbosch (2019) shows that for every $K \geq 1$, for every $g \in \mathbb{G}$, it holds that $f_{K}^{\infty}(g) \subseteq f_{K+1}^{\infty}(g)$, and that for $K \geq n^{\prime}-1$, for every $g \in \mathbb{G}$, it holds that $f_{K}^{\infty}(g)=f_{K+1}^{\infty}(g)=f_{\infty}^{\infty}(g)$.

Jackson and Watts (2002) have defined the notion of a closed cycle. A set of networks $C$ is a cycle if for any $g^{\prime} \in C$ and $g \in C \backslash\left\{g^{\prime}\right\}$, there exists a sequence of improving paths of length 1 connecting $g$ to $g^{\prime}$, i.e. $g^{\prime} \in f_{1}^{\infty}(g)$. A cycle $C$ is a maximal cycle if it is not a proper subset of a cycle. A cycle $C$ is a closed cycle if $f_{1}^{\infty}(C)=C$, so there is no sequence of improving paths of length 1 starting at some network in $C$ and leading to a network that is not in $C$. A closed cycle is necessarily a maximal cycle. For every pairwise stable network $g \in P_{1}$, the set $\{g\}$ is a closed cycle. The set of networks belonging to a closed cycle is non-empty.

The notion of a horizon- $K$ farsighted set is based on two main requirements: horizon- $K$ deterrence of external deviations and horizon- $K$ external stability.

A set of networks $G$ satisfies horizon- $K$ deterrence of external deviations if all possible deviations from any network $g \in G$ to a network outside $G$ are deterred by a threat of ending worse off or equally well off. ${ }^{10}$

Definition 1. For $K \geq 1$, a set of networks $G \subseteq \mathbb{G}$ satisfies horizon-K deterrence of external deviations if for every $g \in G$,

(a) $\forall i j \notin g$ such that $g+i j \notin G$,

$\exists g^{\prime} \in\left[f_{K-2}(g+i j) \cap G\right] \cup\left[f_{K-1}(g+i j) \backslash f_{K-2}(g+i j)\right]$ such that

$\left(Y_{i}\left(g^{\prime}\right), Y_{j}\left(g^{\prime}\right)\right)=\left(Y_{i}(g), Y_{j}(g)\right)$ or $Y_{i}\left(g^{\prime}\right)<Y_{i}(g)$ or $Y_{j}\left(g^{\prime}\right)<Y_{j}(g)$,

(b) $\forall i j \in g$ such that $g-i j \notin G$,

$\exists g^{\prime}, g^{\prime \prime} \in\left[f_{K-2}(g-i j) \cap G\right] \cup\left[f_{K-1}(g-i j) \backslash f_{K-2}(g-i j)\right]$ such that $Y_{i}\left(g^{\prime}\right) \leq Y_{i}(g)$ and $Y_{j}\left(g^{\prime \prime}\right) \leq Y_{j}(g)$.

\footnotetext{
${ }^{10}$ We use the notational convention that $f_{-1}(g)=\emptyset$ for every $g \in \mathbb{G}$.
} 
Condition (a) in Definition 1 captures that adding a link $i j$ to a network $g \in G$ that leads to a network $g+i j$ outside of $G$, is deterred by the threat of ending in $g^{\prime}$. Here $g^{\prime}$ is such that either there is a farsighted improving path of length smaller than or equal to $K-2$ from $g+i j$ to $g^{\prime}$ and $g^{\prime}$ belongs to $G$ or there is a farsighted improving path of length equal to $K-1$ from $g+i j$ to $g^{\prime}$ and there is no farsighted improving path from $g+i j$ to $g^{\prime}$ of smaller length. Condition (b) is a similar requirement, but then for the case where a link is severed. ${ }^{11}$

A set of networks $G$ satisfies horizon- $K$ external stability if from any network outside of $G$ there is a sequence of farsighted improving paths of length smaller than or equal to $K$ leading to some network in $G$.

Definition 2. For $K \geq 1$, a set of networks $G \subseteq \mathbb{G}$ satisfies horizon-K external stability if for every $g^{\prime} \in \mathbb{G} \backslash G, f_{K}^{\infty}\left(g^{\prime}\right) \cap G \neq \emptyset$.

This requirement implies that if we allow players with a degree of farsightedness equal to $K$ to successively create or delete links, they will ultimately reach the set $G$ irrespective of the initial network.

Definition 3. For $K \geq 1$, a set of networks $G_{K} \subseteq \mathbb{G}$ is a horizon- $K$ farsighted set if it is a minimal set satisfying horizon- $K$ deterrence of external deviations and horizon- $K$ external stability.

Herings, Mauleon, and Vannetelbosch (2019) prove that a horizon- $K$ farsighted set of networks exists. For $K=1$, Theorem 3 of Herings, Mauleon, and Vannetelbosch (2019) show that there is a unique horizon-1 farsighted set consisting of all networks that belong to a closed cycle. This result does not carry over to higher levels of $K$.

As shown by Herings, Mauleon, and Vannetelbosch (2019), the collection of horizon- $K$ farsighted sets is independent of $K$ when $K \geq n^{\prime}+1$. Moreover, for every

\footnotetext{
${ }^{11}$ Since the degree of farsightedness of players is equal to $K$, Herings, Mauleon and Vannetelbosch (2019) distinguish farsighted improving paths of length less than or equal to $K-2$ after a deviation from $g$ to $g+i j$ and farsighted improving paths of length equal to $K-1$. In the former case, the reasoning capacity of the players is not yet reached, and the threat of ending in $g^{\prime}$ is only credible if it belongs to the set $G$. In the latter case, the only way to reach $g^{\prime}$ from $g$ requires $K$ steps of reasoning or even more; one step in the deviation to $g+i j$ and at least $K-1$ additional steps in any farsighted improving path from $g+i j$ to $g^{\prime}$. Since this exhausts the reasoning capacity of the players, the threat of ending in $g^{\prime}$ is credible, irrespective of whether it belongs to $G$ or not.
} 
pairwise farsightedly stable set $G_{\infty}$ defined by Herings, Mauleon and Vannetelbosch (2009), there is a set $G^{\prime} \subseteq G_{\infty}$ such that $G^{\prime}$ is a level- $\left(n^{\prime}+1\right)$ farsighted set. ${ }^{12}$

The following theorem of Herings, Mauleon and Vannetelbosch (2019) will be used in the next section to identify the horizon-K farsighted set of criminal networks.

Theorem 1 (Herings, Mauleon and Vannetelbosch (2019)). Consider some $K \geq 2$. If $g \in D_{J}$ for some $J<K$ and for every $g^{\prime} \in \mathbb{G} \backslash\{g\}$ it holds that $g \in f_{K}^{\infty}\left(g^{\prime}\right)$, then $\{g\}$ is a horizon-K farsighted set. If, moreover, $g \in P_{K}$, then $\{g\}$ is the unique horizon-K farsighted set.

Theorem 1 requires that $g \in D_{J}$ for some $J<K$, so we have to show that $g \in f_{J}\left(g^{\prime}\right)$ for all $g^{\prime}$ adjacent to $g$. The higher $J$, the weaker this requirement, so we could replace the requirement $g \in D_{J}$ for some $J<K$ by $g \in D_{K-1}$. To show that $g \in f_{K}^{\infty}\left(g^{\prime}\right)$ for all $g^{\prime} \neq g$, we have to find a sequence of farsighted improving paths of length at most $K$ that connect $g^{\prime}$ to $g$. Very often the analysis of farsighted improving paths of small lengths is already sufficient. The higher $K$, the easier it is to satisfy the conditions of Theorem 1 and to find a singleton horizon- $K$ farsighted set. Finally, to show that $g \in P_{K}$ requires that $f_{K}(g)=\emptyset$. This requirement is more difficult to satisfy for increasing values of $K$.

\section{Horizon- $K$ Farsighted Set of Criminal Networks}

Throughout this section, we assume $n \geq 3$. Figure 1 presents the payoffs for 3 player criminal networks with $B=9$ and $\phi=1$ in expression (1). Table 1 shows the farsighted improving paths for the different possible values of $K$. It can be verified that the farsighted improving paths for the 3-player case do not depend on the specific choices for $B$ and $\phi$.

For the three-player case, we compute the closed cycles and use Theorem 3 in Herings, Mauleon and Vannetelbosch (2019) to conclude that $G_{1}=P_{1}=\left\{g^{1}, g^{2}, g^{3}, g^{7}\right\}$ is the horizon- 1 farsighted set, so $G_{1}$ consists of all pairwise stable networks. There are many networks that are stable when players are myopic.

\footnotetext{
${ }^{12}$ Herings, Mauleon and Vannetelbosch (2009) define a pairwise farsightedly stable set as a set $G_{\infty}$ of networks satisfying horizon- $\infty$ deterrence of external deviations and minimality, but with horizon- $\infty$ external stability replaced by the requirement that for every $g^{\prime} \in \mathbb{G} \backslash G_{\infty}, f_{\infty}\left(g^{\prime}\right) \cap G_{\infty} \neq$ $\emptyset$.
} 


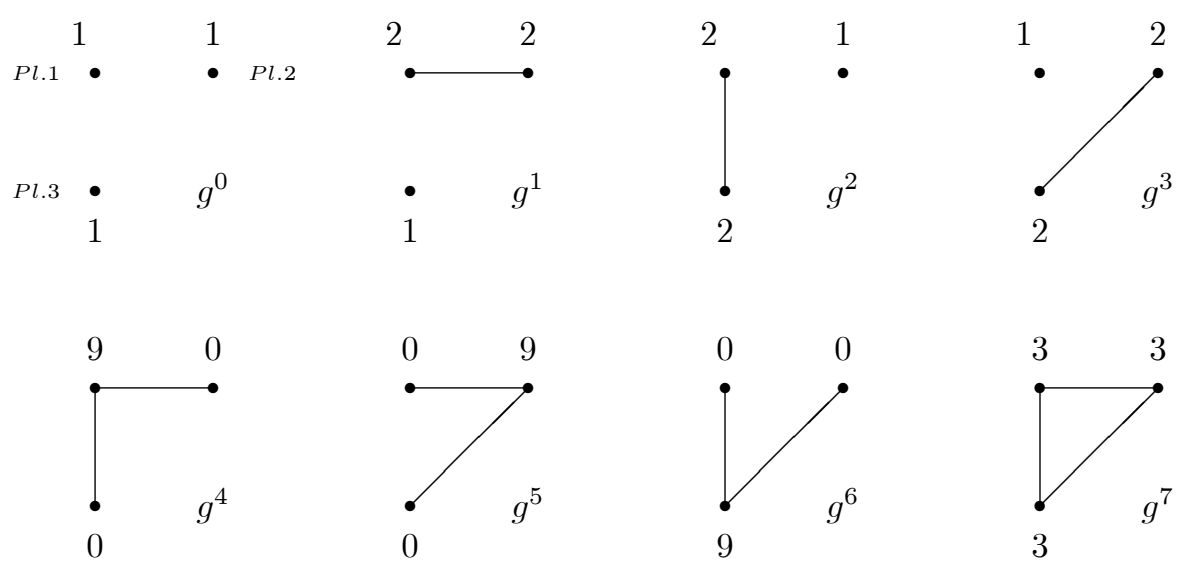

Figure 1: The 3-player criminal networks.

\begin{tabular}{|c||c|c|c|}
\hline$g$ & $f_{1}(g)$ & $f_{2}(g)$ & $f_{K}(g), K \geq 3$ \\
\hline \hline$g^{0}$ & $g^{1}, g^{2}, g^{3}$ & $g^{1}, g^{2}, g^{3}$ & $g^{1}, g^{2}, g^{3}, g^{7}$ \\
\hline$g^{1}, g^{2}, g^{3}$ & & $g^{7}$ & $g^{7}$ \\
\hline$g^{4}$ & $g^{1}, g^{2}, g^{7}$ & $g^{1}, g^{2}, g^{7}$ & $g^{1}, g^{2}, g^{3}, g^{7}$ \\
\hline$g^{5}$ & $g^{1}, g^{3}, g^{7}$ & $g^{1}, g^{3}, g^{7}$ & $g^{1}, g^{2}, g^{3}, g^{7}$ \\
\hline$g^{6}$ & $g^{2}, g^{3}, g^{7}$ & $g^{2}, g^{3}, g^{7}$ & $g^{1}, g^{2}, g^{3}, g^{7}$ \\
\hline$g^{7}$ & & & \\
\hline
\end{tabular}

Table 1: The elements of $f_{K}(g) \backslash\{g\}$ for 3-player criminal networks with $B=9$ and $\phi=1$

For $K \geq 2$, we apply Theorem 1 to show that $G_{K}=\left\{g^{7}\right\}$ is the unique horizon$K$ farsighted set. It holds that $g^{7} \in D_{1}$ and $g^{7} \in f_{2}^{\infty}(g)$ for every $g \neq g^{7}$, so $\left\{g^{7}\right\}$ is a horizon- $K$ farsighted set. Since $g^{7} \in P_{K}$, it follows from Theorem 1 that $\left\{g^{7}\right\}$ is the unique horizon- $K$ farsighted set. If criminals behave myopically, they may not go beyond forming a single link in the three player case. But with a degree of farsightedness of at least 2 , the complete criminal network emerges as the unique prediction.

The remainder of this section is devoted to the analysis of criminal networks with a general number $n$ of players. As in the 3-criminal case, there are many networks that are pairwise stable in the $n$-person case. The complete network is easily verified to be pairwise stable. The generalization of the networks $g^{1}, g^{2}$, and $g^{3}$ for the 3 - 
criminal case to the $n$-criminal case would be any network consisting of complete components, where no two components have the same degree. But also any network with a single component where all players have a degree at least equal to two and one player has a degree that is at least two times higher than the degree of any other player is pairwise stable.

We will argue next that $\left\{g^{N}\right\}$ is a horizon- $K$ farsighted set whenever $K \geq n-1$.

We show first that the complete network is pairwise dominant.

Lemma 1. For criminal networks it holds that $g^{N} \in D_{1}$.

Proof. Consider the network $g^{N}-i j$ for some $i j$. It holds that

$$
d_{i}\left(g^{N}-i j\right)=d_{j}\left(g^{N}-i j\right)<c_{i}\left(g^{N}-i j\right)=c_{j}\left(g^{N}-i j\right),
$$

so

$$
Y_{i}\left(g^{N}-i j\right)=Y_{j}\left(g^{N}-i j\right)=0<Y_{i}\left(g^{N}\right)=Y_{j}\left(g^{N}\right),
$$

and $g^{N} \in f_{1}\left(g^{N}-i j\right)$. We have shown that $g^{N} \in D_{1}$.

We show next that the complete network can be reached from any starting network by repeated application of at most $n-1$ degrees of farsightedness.

Lemma 2. For criminal networks it holds for every $g \in \mathbb{G} \backslash\left\{g^{N}\right\}$ that $g^{N} \in f_{n-1}^{\infty}(g)$. Proof.

Step 1. If $g$ has a component which is not complete, then there is $g^{\prime} \in f_{n-1}(g)$ such that $g \subsetneq g^{\prime}$.

Let $S \in \mathcal{P}(g)$ be a criminal group such that some internal links are missing, $g_{\mid S} \neq g^{S}$.

If for every $i \in S$ it holds that $d_{i}(g)=c_{i}(g)$, so all players in $S$ have the same degree, then any two unlinked players $i$ and $j$ in $S$ create a link to form the network $g+i j$ and improve their payoffs since the increase in their degree increases the share in the loot and lowers the probability of being caught for both players, $\alpha_{i}(g+i j)>\alpha_{i}(g), \alpha_{j}(g+i j)>\alpha_{j}(g), q_{i}(g+i j)<q_{i}(g)$, and $q_{j}(g+i j)<q_{j}(g)$, so $Y_{i}(g+i j)>Y_{i}(g)$ and $Y_{j}(g+i j)>Y_{j}(g)$. We have that $g \rightarrow_{1} g+i j$, so clearly $g+i j \in f_{n-1}(g)$.

If the players in $S$ do not all have the same degree, let $i \in S$ be a player with $d_{i}(g)=c_{i}(g)$. If $c_{i}(g)<\# S-1$, then Player $i$ links with any Player $j$ such that $i j \notin g$ to form the network $g+i j$. It holds that $Y_{i}(g+i j)>Y_{i}(g)>0$ since 
$\alpha_{i}(g+i j) \geq \alpha_{i}(g)$ and $q_{i}(g+i j)<q_{i}(g)$, whereas $Y_{j}(g+i j) \geq Y_{j}(g)$. We have that $g \rightarrow_{1} g+i j$, so clearly $g+i j \in f_{n-1}(g)$.

If the players in $S$ do not all have the same degree and there is a player in $S$ with degree $\# S-1$, then let $i \in S$ be a player with $d_{i}(g)<\# S-1$. Player $i$ consecutively links to all players $j \in S$ such that $i j \notin g$, thereby forming a network $g^{\prime}$ where he has degree $\# S-1$. The payoffs of Player $i$ are in every step equal to $Y_{i}(g)=0$ until the final step, where his payoffs increase to $Y_{i}\left(g^{\prime}\right)>0$. Every player $j$ that $i$ links to has degree below $\# S-1$ and therefore payoffs equal to $0 \leq Y_{j}\left(g^{\prime}\right)$. We have that $g^{\prime} \in f_{\# S-2}(g) \subseteq f_{n-1}(g)$ by Lemma 1 in Herings, Mauleon and Vannetelbosch (2019).

Step 2. If all components of $g$ are complete and $g \neq g^{N}$, then there is $g^{\prime} \in f_{n-1}(g)$ such that $g \subsetneq g^{\prime}$.

The assumptions of Step 2 imply that $g$ consists of at least two criminal groups. Let $S^{1}$ and $S^{2}$ be two criminal groups in $\mathcal{P}(g)$.

If $\# S^{1}=\# S^{2}$, then form a link between a Player $i \in S^{1}$ and a Player $j \in S^{2}$. Since $q_{i}(g)>q_{i}(g+i j)$, we have that

$$
Y_{i}(g)=\frac{1}{n}\left(1-q_{i}(g) \phi\right) B<\frac{\# S^{1}}{n}\left(1-q_{i}(g+i j) \phi\right) B=Y_{i}(g+i j) .
$$

By the same calculation, it follows that $Y_{j}(g)<Y_{j}(g+i j)$, so $g \rightarrow_{1} g+i j$, and therefore $g+i j \in f_{n-1}(g)$.

Otherwise, it holds without loss of generality that $\# S^{1}<\# S^{2}$. Select some player $i \in S^{1}$ and a set $J$ consisting of $\# S^{2}+1-\# S^{1}$ players in $S^{2}$, who link consecutively to Player $i$ to form network $g^{\prime}$. The resulting finite sequence of networks is denoted $g_{0}, \ldots, g_{K}$ with $g_{0}=g$ and $g_{K}=g^{\prime}$. Notice that $K \leq n-1$. We show next that for every $k \in\{0, \ldots, K-1\},\left(Y_{i}\left(g_{k}\right), Y_{j_{k}}\left(g_{k}\right)\right)<\left(Y_{i}\left(g_{K}\right), Y_{j_{k}}\left(g_{K}\right)\right)$, where $j_{k} \in J$ is such that $g_{k+1}=g_{k}+i j_{k}$, thereby proving that $\left(g_{0}, \ldots, g_{K}\right)$ is a farsighted improving path and completing the proof of Step 2.

For every player $j \in J$ we have

$$
d_{j}\left(g_{K}\right)=d_{i}\left(g_{K}\right)=c_{i}\left(g_{K}\right),
$$

and for all other players the degree is strictly less than $c_{i}\left(g_{K}\right)$, so

$$
Y_{j}\left(g_{K}\right)=Y_{i}\left(g_{K}\right)=\frac{\# S^{1}+\# S^{2}}{n} \frac{1}{\# S^{2}+2-\# S^{1}}\left(1-q_{i}\left(g_{K}\right) \phi\right) B .
$$


For $k=0$, we have

$$
\begin{aligned}
Y_{i}\left(g_{0}\right) & =\frac{1}{n}\left(1-q_{i}(g) \phi\right) B<Y_{i}\left(g_{K}\right), \\
Y_{j_{0}}\left(g_{0}\right) & =\frac{1}{n}\left(1-q_{j_{0}}(g) \phi\right) B<Y_{j_{0}}\left(g_{K}\right),
\end{aligned}
$$

where we use $q_{i}\left(g_{0}\right)>q_{i}\left(g_{K}\right)$ and $q_{j_{0}}\left(g_{0}\right)>q_{j_{0}}\left(g_{K}\right)$ to get the strict inequalities.

For $k=1, \ldots, K-1$, it holds that Player $i$ is connected to Player $j_{0}$, so $d_{i}\left(g_{k}\right)<$ $d_{j_{0}}\left(g_{k}\right)=c_{i}\left(g_{k}\right)$, so $\alpha_{i}\left(g_{k}\right)=0$ and $0=Y_{i}\left(g_{k}\right)<Y_{i}\left(g_{K}\right)$. Similarly, it holds that Player $j_{k}$ is connected to Player $j_{0}$, so $d_{j_{k}}\left(g_{k}\right)<d_{j_{0}}\left(g_{k}\right)=c_{j_{k}}\left(g_{k}\right)$, so $\alpha_{j_{k}}\left(g_{k}\right)=0$ and $0=Y_{j_{k}}\left(g_{k}\right)<Y_{j_{k}}\left(g_{K}\right)$.

Step 3. For every $g \in \mathbb{G} \backslash\left\{g^{N}\right\}$, it holds that $g^{N} \in f_{n-1}^{\infty}(g)$.

By combining the results of Step 1 and Step 2, we have that for every $g \in \mathbb{G} \backslash\left\{g^{N}\right\}$, there is $g^{\prime} \in f_{n-1}(g)$ with strictly more links than $g$. Since the complete network $g^{N}$ has $n(n-1) / 2$ links, we find that $g^{N} \in f_{n-1}^{n(n-1) / 2}(g) \subseteq f_{n-1}^{\infty}(g)$.

Using Theorem 1, we prove now that the complete network $\left\{g^{N}\right\}$ is a horizon- $K$ farsighted set for every $K \geq n-1 .^{13}$ Notice that the level of farsightedness needed to sustain the complete network $\left\{g^{N}\right\}$ is quite small when compared to the number of potential networks and the maximum length of paths. ${ }^{14}$

Theorem 2. For criminal networks it holds that $\left\{g^{N}\right\}$ is a horizon-K farsighted set for every $K \geq n-1$.

Proof. By Lemma 1 we have that $g^{N} \in D_{1}$. By Lemma 2 we have that for every $g^{\prime} \in \mathbb{G} \backslash\left\{g^{N}\right\}$ it holds that $g^{N} \in f_{n-1}^{\infty}\left(g^{\prime}\right) \subseteq f_{K}^{\infty}\left(g^{\prime}\right)$, where the inclusion follows from Lemma 2 in Herings, Mauleon and Vannetelbosch (2019). We are now in a position to apply Theorem 1 and conclude that $\left\{g^{N}\right\}$ is a horizon- $K$ farsighted set.

How about the uniqueness of $\left\{g^{N}\right\}$ as a horizon- $K$ farsighted set? It is tempting to use the approach of Theorem 1 and show such a result by proving that $g^{N} \in P_{K}$. However, consider the case with 6 players and let $g^{\prime}=g^{N}-16-26-35-45$. For any value of $B$ and $\phi,{ }^{15}$ we claim that $g^{\prime} \in f_{12}\left(g^{N}\right)$, so $g^{N} \notin P_{12}$. Since the network

\footnotetext{
${ }^{13}$ Herings, Mauleon and Vannetelbosch (2009) show that in the example of criminal networks with $n$ players, the complete network $\left\{g^{N}\right\}$ is a pairwise farsightedly stable set.

${ }^{14}$ Once the network connecting delinquents is endogenous, Calvo-Armengol and Zenou (2004) find that all complete networks, where all players in the pool of criminals are linked to each other, are pairwise stable. Notice that the size of the pool of criminals depends on the wage on the labor market.

${ }^{15}$ We maintain the assumption that $\phi<n /(n-1)$.
} 
$g^{\prime}$ is connected, $d_{1}\left(g^{\prime}\right)=d_{2}\left(g^{\prime}\right)=d_{3}\left(g^{\prime}\right)=d_{4}\left(g^{\prime}\right)=4$, and $d_{5}\left(g^{\prime}\right)=d_{6}\left(g^{\prime}\right)=3$, it holds for any $i \in\{1,2,3,4\}$ that $Y_{i}\left(g^{\prime}\right)=(1 / 4-\phi / 24) B>B / 6=Y_{i}\left(g^{N}\right)$ and for any $j \in\{5,6\}$ that $Y_{j}\left(g^{\prime}\right)=0<B / 6=Y_{j}\left(g^{N}\right)$. The construction of the farsighted improving path is, however, more subtle than simply deleting the links 16, 26, 35, and 45 in some order. Indeed, after the deletion of three such links, there are exactly two players with the maximum degree and they would get strictly lower payoffs by cutting their link, and would be unwilling to do so. The way to avoid this problem requires more farsightedness and involves all players in $\{1,2,3,4\}$ first cutting two of their mutual links, before severing the links with players 5 and 6 , and finally restoring their mutual links. One explicit farsighted improving path results from $g^{N}-12-23-34-41-16-26-35-45+12+23+34+41$ and takes 12 steps. We have denoted the player with an incentive to cut a link first, so -16 for instance means that Player 1 cuts his link with Player 6, whereas -61 would mean that Player 6 cuts his link with Player 1. It can be verified that each step in this farsighted improving path is feasible indeed.

We conclude this section by showing that if criminals are not too farsighted, then $g^{N} \in P_{K}$, so $\left\{g^{N}\right\}$ is the unique horizon- $K$ farsighted set. More precisely, we will from now on consider $K=n-1$. We show first that any network in $f_{n-1}\left(g^{N}\right)$ has a single component involving all players.

Lemma 3. For criminal networks it holds for every $g^{\prime} \in f_{n-1}\left(g^{N}\right)$ that $\mathcal{P}\left(g^{\prime}\right)=\{N\}$.

Proof. Consider the criminal group $S$ of Player 1 in $g^{\prime}$. We show that it contains all players. Suppose it contains only $s \leq n-1$ players. Then, starting from $g^{N}$, those $s$ players have to cut all their links with all other players in $N \backslash S$. This involves at least $s(n-s)$ steps. For fixed $n$, the concavity of $s(n-s)$ in $s$ implies that $s(n-s)$ is minimized at $s=1$ or $s=n-1$. Substitution of these values of $s$ shows the minimum to be equal to $n-1$ at both $s=1$ and $s=n-1$. When the $s$ players cut all their links with all other players in $N \backslash S$, all the players in $N$ are strictly worse off, since the probability of being caught has strictly increased and the probability of winning the loot has decreased, contradicting $g^{\prime} \in f_{n-1}\left(g^{N}\right)$.

We show next that the complete network $g^{N}$ is horizon- $(n-1)$ pairwise stable.

Lemma 4. For criminal networks it holds that $g^{N} \in P_{n-1}$. 
Proof. Suppose $g^{\prime}$ is an element of $f_{n-1}\left(g^{N}\right)$. Let $g_{0}, \ldots, g_{K}$ with $g_{0}=g^{N}$ and $g_{K}=g^{\prime}$ be a farsighted improving path of length $K \leq n-1$. By Lemma 3 it holds that $c_{i}\left(g^{\prime}\right)$ is independent from $i$, so we denote it by $c$. Let $M \subseteq N$ be such that $i \in M$ if and only if $d_{i}\left(g^{\prime}\right)=c$ and denote the cardinality of $M$ by $m$. It cannot be that $m=n$, since then all players have lower payoffs in $g^{\prime}$ than in $g^{N}$ because the probability of being caught is higher in $g^{\prime}$ than in $g^{N}$. Since by Lemma $3 g^{\prime}$ is connected, it follows that $Y_{j}\left(g^{\prime}\right)=0$ for all $j \in N \backslash M$. A player $j \in N \backslash M$ will therefore not sever a link at any network in the farsighted improving path $g_{0}, \ldots, g_{K}$. It follows that

$$
\sum_{i \in M}\left(n-1-d_{i}\left(g^{\prime}\right)\right) \geq \sum_{j \in N \backslash M}\left(n-1-d_{j}\left(g^{\prime}\right)\right) .
$$

Since $d_{i}\left(g^{\prime}\right)>d_{j}\left(g^{\prime}\right)$ whenever $i \in M$ and $j \in N \backslash M$, we have that $m>n / 2$.

Since at least one link $i j$ with $i \in M$ and $j \in N$ is missing in $g^{\prime}$, it follows that the maximum degree in $g^{\prime}$ satisfies $c \leq n-2$.

The number $K$ is equal to the number of times a link $i j$ is severed with $i \in M$ and $j \in N \backslash M$ plus the number of times a link $i j$ is cut with $i, j \in M$ plus the number of link additions. We argue next that lower bounds for these three numbers are given by $2(n-m), 2 m-n-1$, and 1 , respectively.

Since all players in $N \backslash M$ experienced the severance of at least two links, and any such link is cut by a player in $M$, a lower bound for the first number is $2(n-m)$.

For $k=0, \ldots, K$, let $L\left(g_{k}\right)=\left\{i \in N \mid d_{i}\left(g_{k}\right)=n-1\right\}$ be the set of players with degree $n-1$ and let $\ell\left(g_{k}\right)=\# L\left(g_{k}\right)$ be its cardinality. Clearly, it holds that $\ell\left(g^{N}\right)=n$ and $\ell\left(g^{\prime}\right)=0$. Let $k^{\prime}$ be the lowest value of $k$ such that $\ell\left(g_{k}\right) \leq m$ for all $k \geq k^{\prime}$. Since $\ell\left(g_{k}\right)-\ell\left(g_{k+1}\right) \leq 2$, we find that $\ell\left(g_{k^{\prime}}\right)=m$ or $\ell\left(g_{k^{\prime}}\right)=m-1$. The sum of the cardinality $\ell\left(g_{k^{\prime}}\right)$ of $L\left(g_{k^{\prime}}\right)$ and the cardinality $m$ of $M$ is therefore at least $2 m-1$. Since there are only $n$ players, it follows that $\#\left(L\left(g_{k^{\prime}}\right) \cap M\right)$, the cardinality of the set of players in $L\left(g_{k^{\prime}}\right)$ that belong to $M$, is at least $2 m-n-1$.

For all $k \geq k^{\prime}$, for all $i \in L\left(g_{k}\right)$, it holds that $Y_{i}\left(g_{k}\right)>Y_{i}\left(g^{\prime}\right)$, since the loot has to be shared with less or the same number of criminals and the probability of being caught is strictly less when comparing $g_{k}$ to $g^{\prime}$. Such a player $i$ will therefore never choose to sever a link himself, so whenever a link involving player $i \in L\left(g_{k}\right)$ is severed when going from $g_{k}$ to $g_{k+1}$, it must be by a player in $M \backslash L\left(g_{k}\right)$. It follows that $\ell\left(g_{k}\right)-\ell\left(g_{k+1}\right) \leq 1$. Since $\#\left(L\left(g_{k^{\prime}}\right) \cap M\right) \geq 2 m-n-1$, we find that going from $g_{k^{\prime}}$ to $g^{\prime}$ involves the deletion of at least $2 m-n-1$ links $i j$ with $i, j \in M$. 
We argue next that the move from $g_{K-1}$ to $g_{K}$ involves a link addition. Suppose not, then there is $i j$ with $i \in M$ such that $g_{K}=g_{K-1}-i j$ and $Y_{i}\left(g_{K}\right)>Y_{i}\left(g_{K-1}\right)$. Since $d_{i}\left(g_{K-1}\right)=c_{i}\left(g_{K-1}\right)>c_{i}\left(g_{K}\right)=d_{i}\left(g_{K}\right)$, it follows that at $g_{K}, i$ has to share the loot with more criminals and has a higher probability of being caught than at $g_{K-1}$, so $Y_{i}\left(g_{K}\right)<Y_{i}\left(g_{K-1}\right)$, leading to a contradiction. Consequently, the move from $g_{K-1}$ to $g_{K}$ involves a link addition.

We have proved that $K \geq 2(n-m)+2 m-n-1+1=n$, which contradicts our original supposition that $K \leq n-1$. Consequently, it holds that $f_{n-1}\left(g^{N}\right)=\emptyset$.

Using Theorem 1 we prove now that the complete network $\left\{g^{N}\right\}$ is the unique horizon- $(n-1)$ farsighted set.

Theorem 3. For criminal networks it holds that $\left\{g^{N}\right\}$ is the unique horizon- $(n-1)$ farsighted set.

Proof. By Lemma 1 we have that $g^{N} \in D_{1}$. By Lemma 2 we have that for every $g^{\prime} \in \mathbb{G} \backslash\left\{g^{N}\right\}$ it holds that $g^{N} \in f_{n-1}^{\infty}\left(g^{\prime}\right)$. By Lemma 4 it holds that $g^{N} \in P_{n-1}$. We are now in a position to apply Theorem 1 and conclude that $\left\{g^{N}\right\}$ is the unique horizon- $(n-1)$ farsighted set.

We have found that in criminal networks with $n$ criminals, the set consisting of the complete network is a horizon- $K$ farsighted set whenever the degree of farsightedness of the criminals is larger or equal than $(n-1)$. Moreover, the complete network is the unique horizon- $(n-1)$ farsighted set. Hence, we obtain a very sharp prediction for intermediate degrees of farsightedness (i.e., have a degree of farsightedness equal to $n-1$ ), and show that a limited degree of farsightedness (i.e., at least $n-1$ ) is sufficient to recover the predictions obtained in case of completely farsighted criminals. It seems then important to acquire knowledge about the degree of farsightedness of criminals to determine which criminal networks are likely to emerge in the long run. A better knowledge of the structural properties of criminal networks will help understanding the impact of peer influence on delinquent behavior and addressing adequate and novel delinquency-reducing policies.

\section{Conclusion}

We study the criminal networks that will emerge in the long run when criminals are neither fully myopic nor completely farsighted but have some limited degree 
of farsightedness. We adopt the horizon- $K$ farsighted set of Herings, Mauleon and Vannetelbosch (2019) to show how the predictions about stable criminal networks relate to the degree of farsightedness. A horizon- $K$ farsighted set always exists. We find that in criminal networks with $n$ criminals, the set consisting of the complete network is a horizon- $K$ farsighted set whenever the degree of farsightedness of the criminals is larger than or equal to $(n-1)$. Moreover, the complete network is the unique horizon- $(n-1)$ farsighted set. Hence, a limited degree of farsightedness is sufficient to recover the predictions obtained in case of completely farsighted criminals.

\section{Acknowledgments}

Ana Mauleon and Vincent Vannetelbosch are, respectively, Research Director and Senior Research Associate of the National Fund for Scientific Research (FNRS). Financial support from the MSCA ITN Expectations and Social Influence Dynamics in Economics (ExSIDE) Grant No721846 (1/9/2017-31/8/2020), from the Belgian French speaking community ARC project 15/20- 072 of Saint-Louis University Brussels, and from the Fonds de la Recherche Scientifique - FNRS research grant T.0143.18 is gratefully acknowledged.

\section{References}

[1] Ballester, C., A. Calvo-Armengol and Y. Zenou, 2010. Delinquent networks. Journal of the European Economic Association 8, 34-61.

[2] Bezin, E., T. Verdier and Y. Zenou, 2021. Crime, broken families and punishment. American Economic Journal: Microeconomics forthcoming.

[3] Calvo-Armengol, A. and Y. Zenou, 2004. Social networks and crime decisions: the role of social structure in facilitating delinquent behavior. International Economic Review 45, 939-958.

[4] Chwe, M.S., 1994. Farsighted coalitional stability. Journal of Economic Theory 63, 299-325.

[5] Demuynck, T., P.J.J. Herings, R.D. Saulle and C. Seel, 2019. The myopic stable set for social environments. Econometrica, 87, 111-138. 
[6] Dolder, D. van and V. Buskens, 2014. Individual choices in dynamic networks: an experiment on social preferences. Plos One 9, 1-16.

[7] Dutta, B., S. Ghosal and D. Ray, 2005. Farsighted network formation. Journal of Economic Theory 122, 143-164.

[8] Herings, P.J.J., A. Mauleon and V. Vannetelbosch, 2004. Rationalizability for social environments. Games and Economic Behavior 49, 135-156.

[9] Herings, P.J.J., A. Mauleon and V. Vannetelbosch, 2009. Farsightedly stable networks. Games and Economic Behavior 67, 526-541.

[10] Herings, P.J.J., A. Mauleon and V. Vannetelbosch, 2019. Stability of networks under horizon- $K$ farsightedness. Economic Theory 68, 177-201.

[11] Jackson, M.O., 2008. Social and economic networks. Princeton University Press: Princeton, NJ, USA.

[12] Jackson, M.O. and A. Watts, 2002. The evolution of social and economic networks. Journal of Economic Theory 106, 265-295.

[13] Jackson, M.O. and A. Wolinsky, 1996. A strategic model of social and economic networks. Journal of Economic Theory 71, 44-74.

[14] Kirchsteiger, G., M. Mantovani, A. Mauleon and V. Vannetelbosch, 2016. Limited farsightedness in network formation. Journal of Economic Behavior and Organization 128, 97-120.

[15] Lee, L-F., X. Liu, E. Patacchini and Y. Zenou, 2021. Who is the key player? A network analysis of juvenile delinquency. Journal of Business and Economic Statistics forthcoming.

[16] Mauleon, A. and V. Vannetelbosch, 2004. Farsightedness and cautiousness in coalition formation games with positive spillovers. Theory and Decision 56, 291-324.

[17] Mauleon, A., V. Vannetelbosch and W. Vergote, 2011. von Neumann Morgernstern farsightedly stable sets in two-sided matching. Theoretical Economics 6, 499-521. 
[18] Page, F.H., Jr., M. Wooders and S. Kamat, 2005. Networks and farsighted stability. Journal of Economic Theory 120, 257-269.

[19] Page, F.H., Jr. and M. Wooders, 2009. Strategic basins of attraction, the path dominance core, and network formation games. Games and Economic Behavior 66, 462-487.

[20] Patacchini, E. and Y. Zenou, 2008. The strength of weak ties in crime. European Economic Review 52, 209-236.

[21] Ray, D. and R. Vohra, 2015. The farsighted stable set. Econometrica 83, 9771011.

[22] Xue, L., 1998. Coalitional stability under perfect foresight. Economic Theory $11,603-627$. 